\title{
Full mouth rehabilitation using fixed partial denture \& cast partial denture with attachments and conventional lower denture - A case report
}

\author{
Gopinadh Anne ${ }^{1}$, Krishna Kishore Kadiyala $\mathbf{H}^{2}$, Ravi Rakesh Dev J ${ }^{3}$, Mohan Krishna Badisa ${ }^{4, *}$ \\ ${ }^{1}$ Professor \& HOD, ${ }^{2}$ Professor, ${ }^{3}$ Assistant Professor, ${ }^{4}$ PG Student, Dept. of Prosthodontics, Sibar Institute of Dental Sciences, \\ Guntur, Andhra Pradesh
}

*Corresponding Author:

Email: mohankrishnabadisa@gmail.com

\begin{abstract}
A prosthesis delivered should cater to the needs of the patient and also meet the biological, mechanical, and esthetic considerations. Care should be taken in the formulation of treatment plan that the planned prosthesis fulfills the requirements of the patient and the dentist. Among the various methods of oral rehabilitation precision attachments are viable alternative to join fixed (FDP) and cast partial dentures (CPD) and thereby avoiding cumbersome procedures. The advantages of attachment retained CPD are the improvements in esthetics which eliminates the clasp assembly and biomechanics. This article describes the treatment sequence and technique for the use of attachments in therapy of combining FDP/CPD of patient reported with dislodged cantilever fixed prosthesis.
\end{abstract}

\section{Introduction}

Esthetically and functionally successful prosthetic rehabilitation requires careful attention and meticulous treatment planning. Rehabilitation of partially edentulous arch can be challenging when it is a distal extention situation classified under Kennedy's class I and class II situations. ${ }^{(1)}$ The use of fixed dental prosthesis(FDPs) in oral rehabilitation may not be recommended when the remaining teeth are unable to withstand masticatory loadings. Thus, from the biomechanical point of view, the use of dental implants may be the choice, provided that prerequisites are fulfilled. ${ }^{(2-4)}$ When the use of dental implants and/or conventional FDPs is limited or not indicated, association between an FDP and cast partial denture (CPD) by means of attachments becomes an important alternative to a conventional clasp-retained CPD. ${ }^{(5-7)}$ Attachments are classified as semi-precision and precision devices. Semi-precision attachments are cast from calcinable patterns, while in precision attachments, the patrix-matrix portions are prefabricated on a metal alloy. The casting procedures used for semi-precision attachments may result in inaccuracies, which may detrimentally affect the fit between the components, reducing the resistance to attrition wear and impairing the insertion/removal path of the denture. ${ }^{(8)}$ Extra coronal attachments exhibit hinge, vertical and rotational movements during function. These attachments allow free movement of the prosthesis to distribute potentially destructive forces away from the abutments to supportive bone and tissue. ${ }^{(9)}$ Removable dentures associated with attachments also exhibit some negative aspects: extensive dental crown preparation, ${ }^{(10,11)}$ financial burden, time-consuming and complex clinical and laboratory procedures. ${ }^{(11,12)}$ Other relevant aspects that must be pointed out are the integrity of the metal surfaces in contact with one another, in which longevity is related to their resistance to attrition wear, ${ }^{(10,12)}$ in addition to the difficulty in performing repairs. ${ }^{(16)}$ Moreover, there are other possible disadvantages to consider, such as the abutment crown height of 4.0 to $6.0 \mathrm{~mm}$ required for a suitable retention and attachment functionality, need for root canal treatment in some teeth in an unfavorable position, and more invasive crown preparations for intracoronal attachments. ${ }^{(10,11)}$ Finally, in addition to taking the biomechanical aspects into consideration, periodic follow-up is essential to avoid damage to the support structures and guarantee adequate long-term function and esthetics. ${ }^{(6,14-16)}$

This article describes a maxillary rehabilitation using a combination of Fixed Dental Prosthesis \& Cast Partial Denture therapy with extracoronal precision attachments \& mandibular rehabilitation using conventional denture.

\section{Case Report}

A 56 year old woman was referred to Department of Prosthodontics with chief complaint of pain in upper right back tooth region with dislodged full mouth prosthesis which she was disappointed by the esthetics and masticatory efficiency. Orthopantamograph (OPG) revealed upper cantilever FDP and poorly maintained mandibular teeth. Periapical abscess was presented in the region of 15 . Clinical and radiographic examinations revealed a lack of posterior support, an evident loss of occlusal vertical dimension (OVD) Turner Missirlian classification Category 1 , and alteration in the occlusal plane. (Fig. 1) The patient was explained about the treatment procedure which involved the extraction of lower remaining mandibular teeth and removal of upper dislodged cantilever FDP and extraction of 15 . The patient was explained about the treatment options possible. (Fig. 2) 


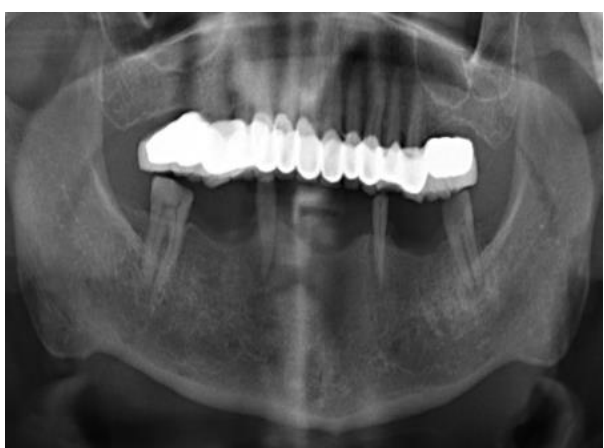

Fig. 1 : Pre OPG showing cantilever FPD

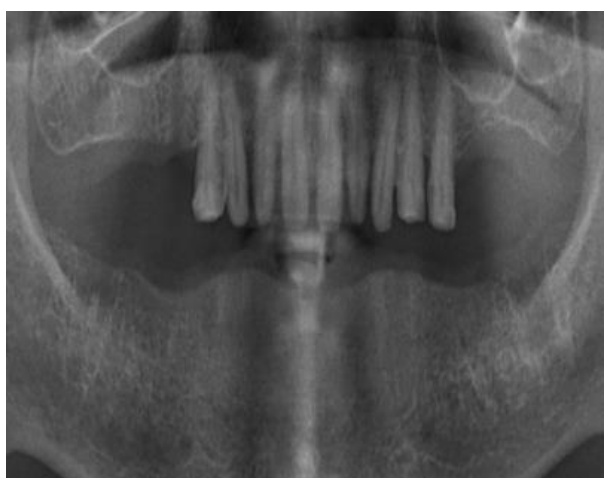

Fig. 2: Post OPG after removal of cantilever FPD

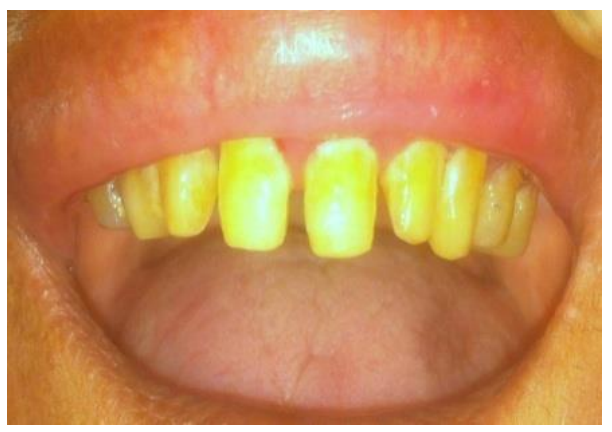

Fig. 3 : Pre operative view

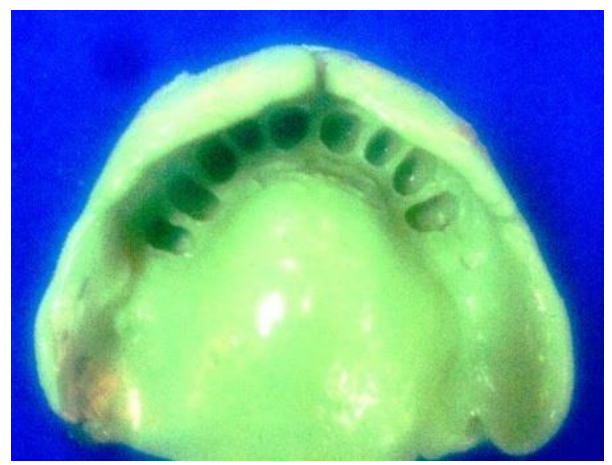

Fig. 4 : Final impression with light body elastomer

The dislodged prosthesis was removed with crown remover. (Fig. 3) After nonsurgical periodontal therapy and analysis of the diagnostic casts mounted on a semiadjustable articulator, treatment planning consisted of a maxillary rehabilitation by means of an association between tooth-supported FDP (maxillary first premolar to left second premolar) and CPD with attachments. This therapeutic modality was selected based on the large prosthetic space and the patient's maxillary bone width and height condition, mainly on the right area, which would require bone grafts to obtain a ridge augmentation. The patient was informed about the possible therapeutic modalities and opted for the related treatment. This therapeutic alternative was less complex and time-consuming. In addition, the use of dental implants in the maxilla would not significantly change the treatment planning for the anterior teeth regarding their periodontal condition. Even if an attachmentretained CPD was not used, these teeth would be splinted to form a stabilized polygon, achieving better long term prognosis. Based on the financial status the placement of implants was ruled out.

The maxillomandibular relationship, including reestablishment of the curves of Spee and Wilson and the OVD, was recorded with occlusion rims and an acrylic resin template, according to the metric, phonetic, and esthetic methods. The maxillary cast was oriented on the semi adjustable articulator with a facebow record and the mandibular cast was mounted. The artificial teeth were positioned for an esthetic and functional clinical evaluation. After this, maxillary interim prostheses (anterior crowns and RPD) were obtained.

Tooth modifications were done and parallel guide planes were obtained on $14 \& 25$. Gingival retraction was done using chemomechanical method (Ultrapak E impregnated with racemic epinephrine hydrochloride) and impression was made with heavy \& light body elastomeric impression material (Fig. 4). After that, the copings of the maxillary anterior teeth were cast with cobalt-chromium alloy. Two-part rigid extracoronal precision attachments (OT CAP, Rhein 83 Inc, USA) with a vertical freedom of movement and an activation portion were cast on the distal surface of the maxillary right first premolar and left second premolar. Extra coronal OT CAP are castable attachments with elastic retention. With its elasticity it is possible to control the flexure and construct a resilient and shock absorbing prostheses. The patrix portions were positioned during the fabrication of the crown wax patterns using a dental surveyor. The casting procedures were executed normally to obtain a rigid connection between the FPD and the patrix portion (Fig. 5). Additional care was taken during the finishing and sandblasting procedures of the casted FPD to avoid abrasive wear of the attachment. As the matrix portion need not be welded to the framework, it was picked up from the patrix portion using acrylic resin. This procedure facilitates long-term repair and/or attachment activation or replacement. 


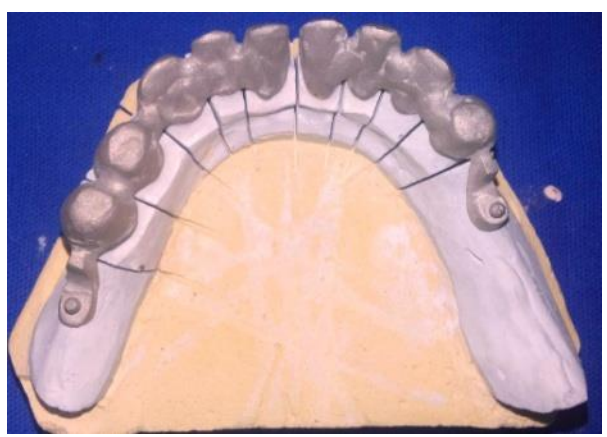

Fig. 5: Impression copings

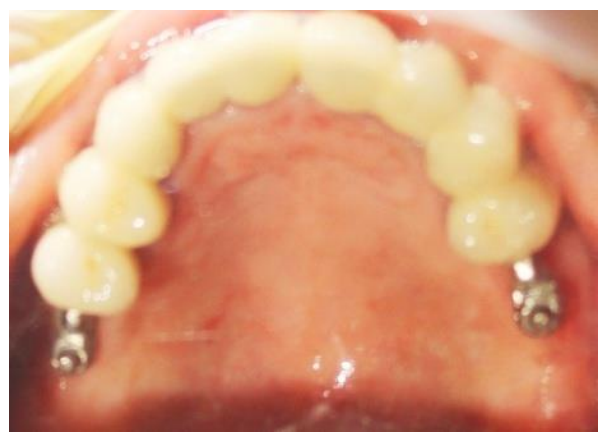

Fig. 6: FPD with Patrix component

The metal copings were clinically examined and the marginal fit was verified. Keeping the metal copings on the prepared teeth an pick up impression was made with monobody elastomeric impression material. An adequate interocclusal distance allowed ceramic application (Fig. 6). The dental surveyor was again used to check the previously established insertion/removal path of the CPD. The FDP/cast assembly was duplicated with reversible hydrocolloid, and a refractory cast was produced. Single palatal strap major connector was designed. The artificial teeth were selected and positioned using the interim prostheses as form and color reference (Fig. $7 \&$ 8). O-Ring is held into the denture base acrylic (matrix portion) by a metal ring. This allows for ease in replacement of the rubber O-Rings if they are worn out in the future with minimal damage. To ensure adequate seating during FDP cementation, the prostheses were attached extraorally, and glass ionomer cement was used. This procedure must be carried out when attachments are used for the association of an FDP/RPD, because a minimal error during FDP cementation may compromise the oral rehabilitation. (Fig. 9)

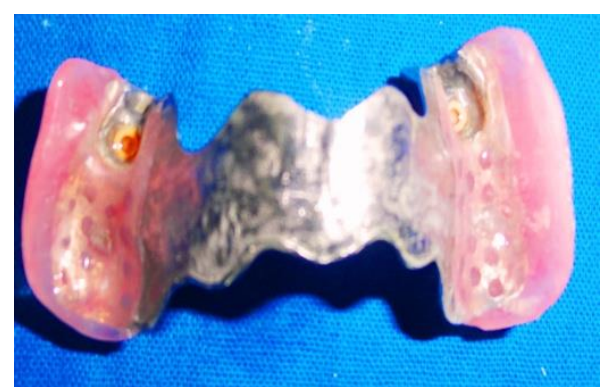

Fig. 7: CPD Intalagio surface with 'O' ring

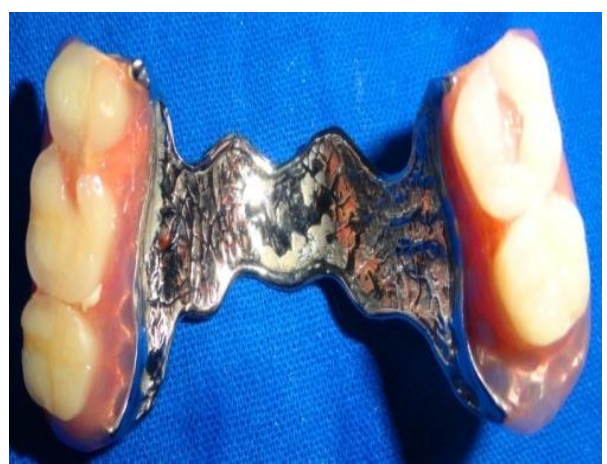

Fig. 8: CPD Occlusal surface

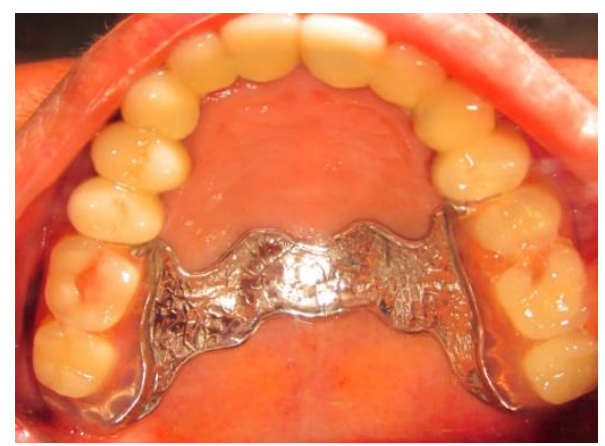

Fig. 9: FPD with Precision Attachments

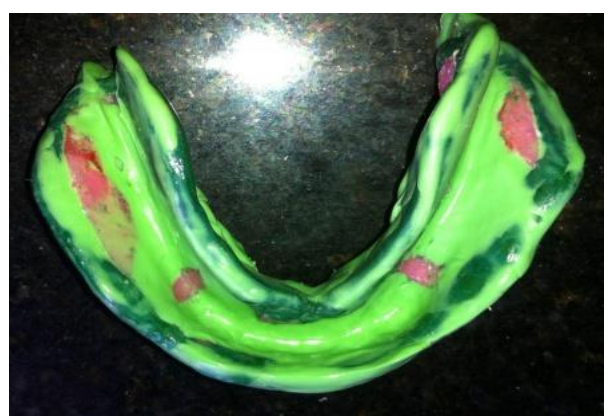

Fig. 10: Lower Final Impression 


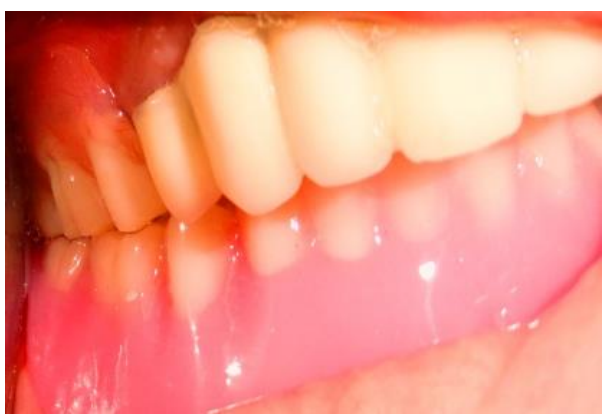

Fig. 11: complete prosthesis insitu

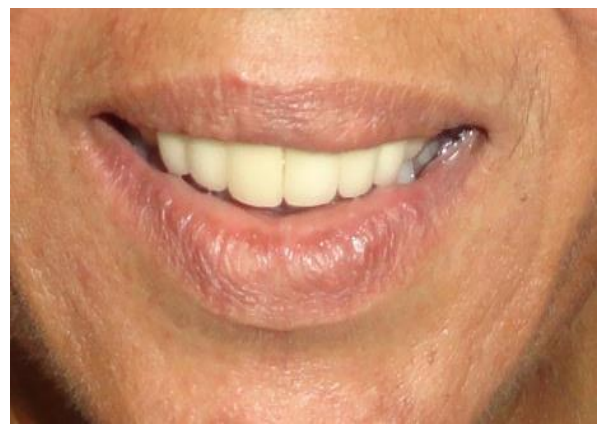

Fig. 12: Frontal Smile

Once the maxillary rehabilitation is done mandibular lower conventional denture was processed. Final impression was made with Light body elastomeric impression material. (Fig. 10) Bite registration was done and teeth arrangement was done. Final prosthesis was given. (Fig. 11) The patient received hygiene and care instructions in writing and learned how to take care of his prostheses. During 1and 2 week control appointments, and after 6,12 months follow-up, an enhanced esthetic appearance and improved retention could be observed. (Fig. 12)

\section{Summary}

Full mouth rehabilitation using an FDP/CPD with attachments is one of the most conservative and best indicated therapeutic modalities considering the limiting bone condition and the financial status of the patient. Furthermore, this treatment option provides a better esthetic appearance and improved retention and function than does a conventional clasp-retained CPD within the biomechanical principles.

\section{References}

1. Mc Craken's Removable partial denture prosthodontics 12th edition. Pg 12.

2. Chronopoulos V, Sarafianou A, Kourtis S. The use of dental implants in combination with removable partial dentures: a case report. J Esthet Restor Dent 2008;20:355-364; discussion 365.

3. Fugazzotto PA, Lightfoot WS. Maximizing treatment outcomes with removable partial prosthesis through the inclusion of implants and locator attachments. J Mass Dent Soc 2010;59:20-22.
4. Turkyilmaz I. Use of distal implants to support and increase retention of a removable partial denture: a case report. J Can Dent Assoc 2009;75:655-658.

5. Chikunov I, Doan P, Vahidi F. Implant-retained partial overdenture with resilient attachments. J Prosthodont 2008;17:141-148.

6. Vermeulen AH, Keltjens HM, van't Hof MA, et al. Tenyear evaluation of removable partial dentures: survival rates based on retreatment, not wearing and replacement. J Prosthet Dent 1996;76:267-272.

7. Viennot S, Dalard F, Malquarti G, et al. Combination fixed and removable prostheses using a $\mathrm{CoCr}$ alloy: a clinical report. J Prosthet Dent 2006;96:100-103 Leupold RJ, Faraone KL: Etched castings as an adjunct to mouth preparation for removable partial dentures. J Prosthet Dent 1985;53:655-658.

8. Zinner ID, Miller RD, Parker HM, et al. Prefabricated metal intracoronal semi-precision attachments for removable partial dentures. Int J Prosthodont 1989;2:357364.

9. Weaver S.M. Precision attachments and their advantages in respect to underlying tissues. J Am Dent Assoc 1938;25:1250-59.

10. Burns DR, Ward JE. Review of attachments for removable partial denture design: 1. Classification and selection. Int J Prosthodont1990;3:98-102.

11. Renner RP: Semi-precision attachment-retained removable partial dentures. Quintessence Dent Technol 1994;17:137-144.

12. Sadig W, Fahmi F. The modified swing-lock: a new approach. J Prosthet Dent 1995;74:428-431.

13. Akaltan F, Kaynak D. An evaluation of the effects of two distal extension removable partial denture designs on tooth stabilization and periodontal health. J Oral Rehabil 2005;32:823-829.

14. Wagner B, Kern M. Clinical evaluation of removable partial dentures 10 years after insertion: success rates, hygienic problems, and technical failures. Clin Oral Investig 2000;4:74-80.

15. Wolf K, Ludwig K, Hartfil $\mathrm{H}$, et al. Analysis of retention and wear of ball attachments. Quintessence Int 2009;40:405-412.

16. Wostmann B, Balkenhol M, Weber A, et al. Long-term analysis of telescopic crown retained removable partial dentures: survival and need for maintenance. J Dent 2007;35:939-945. 